\title{
Growth-allometry relations in Salix species and families, having different tree form and being under different mating design
}

\author{
by Filipos A. Aravanopoulos and Louis Zsuffa ${ }^{1}$
}

\begin{abstract}
Regression techniques were used to estimate biomass for different genetic entries in a breeding program. Growth (biomass production) in Salix amygdaloides and $S$. eriocephala was correlated to height of the major stem, basal diameter of the major stem, number of stems larger or equal to $1.5 \mathrm{~cm}$, number of stems smaller than $1.5 \mathrm{~cm}$. In $S$. amygdaloides (a tree-form willow), basal diameter alone was a good predictor of growth. In $S$. eriocephala (a shrub), height of the major stem and the number of stems greater or equal to $1.5 \mathrm{~cm}$ were the best estimators of growth. Simpler models were developed in $S$. amygdaloides families versus $S$. eriocephala families, and in full-sib families versus half-sib families.
\end{abstract}

Des techniques de régression ont été utilisées dans le but d'estimer la quantité de biomasse produite par différentes sélections génétiques effectuées lors d'un programme de reproduction. La croissance (la production de biomasse) du Salix amygdaloides et du $S$. eriocephala a été corrélée selon la hauteur de la tige principale, le diamètre à la souche de la tige principale, le nombre de tiges dont le diamètre est supérieur ou égal à $1.5 \mathrm{~cm}$, ainsi que selon le nombre de tiges dont le diamètre est inférieur à $1.5 \mathrm{~cm}$. Chez le $S$. amygdaloides (un saule arborescent), le diamètre à la souche en lui-même était un bon indicateur de la croissance. Chez le $S$. eriocephala (un arbuste), la hauteur de la tige principale ainsi que le nombre de tiges dont le diamètre est supérieur ou égal à $1.5 \mathrm{~cm}$ constituaient les meilleurs indicateurs de la croissance. Des modèles simples ont été élaborés pour les familles issues du $S$. amygdaloides par opposition aux familles issues du $S$. eriocephala, ainsi que pour les familles de pleins germains par opposition aux familles de descendance uniparentale.

\section{Introduction}

Salix L. species (willows) are well known for their wide distribution and large variability. There are over 500 species of willow shrubs and trees (Argus 1986), endemic to Europe, Asia, Africa, North and South America. Fiftyfour of these species are considered important for biomass production systems (Stott 1984). Native to North America are about 70 species and about half of these could be of importance for biomass production (Mosseler 1987). For over a decade interest has been growing in the use of willows as a source of short rotation woody biomass for energy and chemicals (Zsuffa 1983). High levels of genetic diversity distributed over a plethora of willow species and untouched natural reserves provide unique opportunities for genetic manipulation and intensive breeding. Short rotation willow culture of genetically improved high yielding clones can produce significant new crops of biomass and secure new raw material, especially for use in industry, essentially in perpetuity.

Predicting biomass yields is important in genetic studies of willows and willow biomass research. Allometric relationships can be used for this purpose. Such relationships allow for field estimates of biomass production, and manipulation of harvest rotation according to specific needs. Most importantly, estimation does not involve destructive sampling which may pose health problems to the plants, and would influence future development and bias test results. Furthermore, destructive sampling is time consuming especially in stands that have grown for more than one season (Verwijst and Nordh 1992).

In this paper we attempt to establish allometric equations for different genetic entries and, in this way, to link

${ }^{1}$ Faculty of Forestry, University of Toronto, Toronto, Ontario, M5S 3B3 allometric work to genetic studies. We hypothesize that allometry is (at least partly) genetically determined, and the pattern of allometric relations fits genetic subdivisions. We envisage our estimation approach as most suited at this point for researchers who have to manage large numbers of family tests, although some of the developed models can lead to more practical applications in future. The investigation of correlations between biomass and allometric characteristics in two types of willow species is reported. The biomass and growth characteristics of willow species established as seedlings in the field were assessed in contrast to other reports in this area which mainly refer to coppice (plantations established via rooted cuttings). Pertinent results from coppice-grown material will be presented and relationships compared among biomass and plant morphology in a successive communication.

\section{Materials and Methods}

Two promising North American willows for biomass production Salix amygdaloides March. and S. eriocephala Michx. (Zsuffa 1983) were studied. These species are morphologically different. S. amygdaloides (peach leaved willow) has a tree form, attaining heights of between 10 and $20 \mathrm{~m}$ usually with one main stem up to $40 \mathrm{~cm}$ in diameter (Mosseler 1987). S. eriocephala, one of the most vigorous North American willows, is a shrub species with many stems averaging between $3 \mathrm{~m}$ and $4 \mathrm{~m}$ in height (Mosseler 1987). The disparity of forms in these species impose use of different allometric parameters and equations which could explain the biomass variability in a statistical model.

Five $S$. amygdaloides families (full-sibs) and ten $S$. eriocephala families (6 full-sibs and 4 half-sibs) were studied (Table 1). Seedling family trials were established using a complete randomized block design at the Ontario Tree Improvement and Forest Biomass Institute near Toronto, 
Table 1. Families used in this study

\begin{tabular}{ll}
\hline Family number & \multicolumn{1}{c}{ Cross } \\
\hline & Salix amygdaloides \\
1 & SAM259 $\times$ SAM315 \\
2 & SAM44 $\times$ SAM282 \\
3 & SAM272 $\times$ SAM282 \\
4 & SAM44 $\times$ SAM315 \\
5 & SAM259 $\times$ SAM292 \\
& S. eriocephala \\
6 & ERIO259 $\times$ ERIO292 \\
7 & ERIO16 $\times$ ERIO307 \\
8 & ERIO16 $\times$ ERIO276 \\
9 & ERIO16 $\times$ ERIO263 \\
10 & ERIO269 $\times$ ERIO263 \\
11 & ERIO16 $\times$ ERIO292 \\
12 & ERIO39 \\
13 & ERIO28 \\
14 & ERIO21 \\
15 & ERIO16 \\
\end{tabular}

as part of a larger trial. The planting sites were silty-clay loam hill-tops on former agricultural land and the spacing was $1 \mathrm{~m} \times 1 \mathrm{~m}$. Hence this study was both site and climate specific. Every family was represented in each of the six blocks with a four-tree plot, thus the total family sample size was 24 ; the test was surrounded by a triple border row. After two years of growth, the following traits were measured on every individual tree: (a) height of the major stem to the nearest $\mathrm{cm}$, (b) basal diameter of the major stem to the nearest $\mathrm{mm}$, (c) number of stems with basal diameter larger than or equal to $1.5 \mathrm{~cm}$ ("large" stems), and (d) number of stems with basal diameter smaller than $1.5 \mathrm{~cm}$ ("small" stems). Subsequently, the trials were harvested and the total leafless above ground oven dry biomass was measured to the nearest gram using a procedure described by Mosseler (1987).

The statistical analysis involved general linear model (GLM) procedures employing SAS (SAS Institute Inc.). Stepwise multiple regression - maximum $R^{2}$ improvement, was used for testing various models. Multiple regression and stepwise multiple regression for correlating biomass production with allometric data, have been used in similar forestry studies (Auclair and Cabanetes 1981, Parde 1980, Ledig 1974, Swank and Shreuder 1974, Berry 1973, Kozak 1973, Nemeth 1973, Ribe 1973, Baskerville 1965). Analysis was performed in the families within the species level. To normalize and linearize the data, and to eliminate as much environmental variance and block effects as possible, biomass measurements and associated plot means were transformed to the logarithmic scale, and all analyses were based on deviations of each individual from its plot mean, which is also a measure of relative-to-plot growth. For the evaluation and selection of multiple regression models (general form: $y=b_{0}+b_{1} x_{1}+\ldots+b_{i} x_{i}$ ), we considered (a) the global $F$-test that encompasses all "b" parameters to determine whether the independent variables are contributing to the relationship and (b) the multiple coefficient of determination $\left(R^{2}\right)$ as well as the Mallow's $C(p)$ value, (McClave and Dietrich 1982). The maximum $R^{2}$ technique was used for obtaining the best models in each species and family. This technique is considered superior to the stepwise multiple regression and almost as good as all possible regressions (McClave and Dietrich 1982). The interaction between basal diameter and height (diameter-square $x$ height) was added as a covariable in the models of both species. This product was usually found to be critical in describing adequately the pattern of biomass production (Parde 1980, Schaegel 1975).

\section{Results and Discussion}

The growth performance of $S$. amygdaloides and S. eriocephala according to the variables measured and their biomass production were summarized (Table 2). Both linear and polynomial models were tested. Considerable variability has been observed between the families of $S$. amygdaloides. Statistically significant linear and polynomial models were developed for each family in most cases. From the selected models, those which employed the least number of variables are presented (Table $3 a$ and $b$ ). Similarly a large number of linear and polynomial models were tested in $S$. eriocephala. The best of these for each family are presented (Table $4 \mathrm{a}$ and $\mathrm{b}$ ). It was not possible to develop linear models for families \# 2, 3, 9, and polynomial models for families \# 7, 8, 9 .

The same variables were not good biomass estimators for both species. In $S$. amygdaloides basal diameter was by far the best estimator. This result is in agreement with other reports on tree species, in which diameter or girth are considered the best biomass estimators (Auclair and Cabanetes 1981, Schaegel 1975, Ribe 1973, Baskerville 1965). The second important variable for biomass production was height. In S. eriocephala the number of "large" stems and height were the best estimators. This species generally produces several major stems of analogous growth; consequently, the significance of the number of stems as a correlating variable should be expected. Differences among families in the second and third best estimator provide an indication of considerable family variability, a notion which is in full agreement with the results published by Mosseler et al. (1988). Correlation matrices for all independent variables showed only small insignificant correlations between the independent variables, indicating that each variable carries some indispensable amount of information.

The different forms of these two species provide a possible reason for the observed differences. In Salix amygdaloides the models were simpler and more accurate than in S. eriocephala. In the former, most of the biomass is in the main stem. In the latter, the biomass is scattered in many large and small stems, thus it is more difficult to provide accurate estimations. In light of the high variation

Table 2. Growth performance and biomass production of Salix amygdaloides (SAM) and S. eriocephala (ERIO) after 2.5 growing seasons

\begin{tabular}{lllll}
\hline Variables & Species & Mean \pm SE & Range & CV \\
\hline Height $(\mathrm{m})$ & SAM & $2.20 \pm 0.05$ & $1.56-2.67$ & 13.23 \\
& ERIO & $2.08 \pm 0.04$ & $1.55-3.36$ & 10.98 \\
B. Diam. $(\mathrm{cm})$ & SAM & $2.22 \pm 0.06$ & $1.18-2.73$ & 16.25 \\
& ERIO & $2.37 \pm 0.04$ & $1.52-3.25$ & 13.39 \\
Large Stems & SAM & $1.13 \pm 0.11$ & $0.25-6.00$ & 52.37 \\
& ERIO & $5.01 \pm 0.02$ & $1.75-8.25$ & 31.54 \\
Small Stems & SAM & $0.38 \pm 0.07$ & $0.00-1.75$ & 104.05 \\
& ERIO & $2.78 \pm 0.16$ & $0.25-6.00$ & 45.21 \\
Biomass $(\mathrm{kg})$ & SAM & $0.26 \pm 0.02$ & $0.12-0.40$ & 33.37 \\
& ERIO & $1.36 \pm 0.05$ & $0.52-0.68$ & 30.13 \\
\hline
\end{tabular}


Table 3a. Linear models describing biomass production in Salix amygdaloides full-sib families ${ }^{1}$

\begin{tabular}{|c|c|c|c|c|c|}
\hline Fam.\# & Model & $\mathbf{R}^{2}$ & $C(p)$ & $\mathbf{F}$ & $\operatorname{Pr}>\mathrm{F}$ \\
\hline 1 & $y=-0.659+38.14 x_{2}+0.085 x_{4}$ & 0.961 & 1.39 & 36.84 & 0.008 \\
\hline 2 & $y=-0.596+0.288 x_{1}+0.241 x_{3}^{4}$ & 0.979 & 1.25 & 71.78 & 0.003 \\
\hline 3 & $y=-0.411-0.061 x_{1}+35.83 x_{2}$ & 0.852 & 1.55 & 8.65 & 0.006 \\
\hline 4 & $y=-0.517=34.27 x_{2}$ & 0.983 & 1.47 & 233.06 & $<0.001$ \\
\hline 5 & $y=0.07+0.151 x_{1}-0.018 x_{4}$ & 0.897 & 1.13 & 13.11 & 0.033 \\
\hline
\end{tabular}

${ }^{1} x_{1}$ : height of major stem $(\mathrm{m}) ; x_{2}$ : basal diameter of major stem $(\mathrm{cm}) ; x_{3}$ : number of stems greater than or equal to $1.5 \mathrm{~cm} ; x_{4}:$ number of stems smaller than $1.5 \mathrm{~cm} ; y$ : biomass $(\mathrm{kg})$

Table 3b. Polynomial models describing biomass production in Salix amygdaloides full-sib families ${ }^{1}$

\begin{tabular}{|c|c|c|c|c|}
\hline Fam.\# & Model & $\mathbf{R}^{2}$ & $\mathbf{F}$ & $\operatorname{Pr}>\mathbf{F}$ \\
\hline 1 & $y=0.09-181344.4 x_{2}{ }^{4}-0.089 x_{1}-0.02 x_{3}+138.75 x_{1}{ }^{2} x_{2}$ & 0.998 & 2007.5 & 0.020 \\
\hline 2 & $y=0.046+0.012 x_{1}+0.016 x_{3}+0.001 x_{4}+8.127 x_{1} x_{2}{ }^{2}$ & 0.997 & 957.2 & 0.020 \\
\hline 3 & $y=0.065+160204.1 x_{2}{ }^{4}-4.507 x_{2}$ & 0.960 & 8.6 & 0.060 \\
\hline 4 & $y=0.076+173057.4 x_{2}^{4}-4.944 x_{2}-0.005 x_{3}$ & 0.998 & 414.2 & 0.009 \\
\hline 5 & $y=-0.12+0.111 x_{1}+0.008 x_{4}-0.008 x_{4}^{2}$ & 0.948 & 12.2 & 0.077 \\
\hline
\end{tabular}

${ }^{1} x_{1}$ : height of major stem $(\mathrm{m}) ; x_{2}$ : basal diameter of major stem $(\mathrm{cm}) ; x_{3}$ : number of stems greater than or equal to $1.5 \mathrm{~cm} ; x_{4}:$ number of stems smaller than $1.5 \mathrm{~cm} ; y$ : biomass $(\mathrm{kg})$

Table 4a. Linear models describing biomass production in Salix eriocephala full-sib and half-sib families ${ }^{1}$

\begin{tabular}{clllcc}
\hline Fam.\# & Model & $\mathbf{R}^{2}$ & $\mathbf{C}(\mathbf{p})$ & $\mathbf{F}$ & Pr>F \\
\hline 1 & $y=1.959-45.49 x_{2}+0.093 x_{3}-0.116 x_{4}$ & 0.997 & 3.04 & 206.8 & 0.005 \\
4 & $y=-0.17+17.05 x_{2}+0.196 x_{3}$ & 0.954 & 1.16 & 31.50 & 0.01 \\
5 & $y=-0.914+0.351 x_{3}+0.118 x_{4}$ & 0.837 & 0.84 & 28.96 & 0.034 \\
6 & $y=-0.983+49.31 x_{2}+0.205 x_{3}$ & 0.959 & 1.47 & 35.30 & 0.008 \\
7 & $y=1.678-0.703 x_{1}-30.38 x_{2}+0.356 x_{3}+0.44 x_{4}$ & 0.999 & 5.00 & 614.4 & 0.001 \\
8 & $y=-4.83+2.124 x_{1}+0.086 x_{3}$ & 0.910 & 1.08 & 15.17 & 0.027 \\
10 & $y=-3.722+1.471 x_{1}+0.184 x_{3}$ & 0.964 & 2.29 & 40.67 & 0.07 \\
\hline
\end{tabular}

${ }^{1} x_{1}$ : height of major stem $(\mathrm{m}) ; x_{2}$ : basal diameter of major stem $(\mathrm{cm}) ; x_{3}$ : number of stems greater than or equal to $1.5 \mathrm{~cm} ; x_{4}:$ number of stems smaller than $1.5 \mathrm{~cm} ; y$ : biomass $(\mathrm{kg})$

Table 4b. Polynomial models describing biomass production in Salix eriocephala full-sib and half-sib families ${ }^{1}$

\begin{tabular}{lllrr}
\hline Fam.\# & Model & R2 & F & Pr>F \\
\hline 1 & $y=1.746-2459.9 x_{1} x_{2}{ }^{2}+0.03 x_{3}{ }^{3}$ & 0.986 & 106.04 & 0.002 \\
2 & $y=-597.7+356.4 x_{1}-1369.3 x_{2}-751534.9 x_{1} x_{2}{ }^{2}+61214931.1 x_{2}{ }^{3}-0.012 x_{3}{ }^{3}$ & 0.998 & 212.42 & 0.051 \\
3 & $y=12.98-0.003 x_{1}{ }^{6}-1.486 x_{3}$ & 0.849 & 8.44 & 0.059 \\
4 & $y=176.4-82.8 x_{1}+0.109 x_{1}{ }^{6}+1.582 x_{3}$ & 0.981 & 34.83 & 0.028 \\
5 & $y=92.4-46.4 x_{1}+0.09 x_{1}{ }^{6}+0.026 x_{3}{ }^{3}$ & 0.977 & 28.96 & 0.034 \\
6 & $y=68.29-31.21 x_{1}+0.038 x_{1}{ }^{6}+0.024 x_{3}{ }^{3}$ & 0.999 & 614.4 & 0.001 \\
10 & $y=153-69.42 x_{1}+0.086 x_{1}{ }^{6}+0.018 x_{3}$ & 0.992 & 83.83 & 0.012 \\
\hline
\end{tabular}

${ }^{1} x_{1}$ : height of major stem $(\mathrm{m}) ; x_{2}$ : basal diameter of major stem $(\mathrm{cm}) ; x_{3}$ : number of stems greater than or equal to $1.5 \mathrm{~cm} ; x_{4}:$ number of stems smaller than $1.5 \mathrm{~cm} ; y$ : biomass $(\mathrm{kg})$

present between and within families, it was surprising that similar statistical models that could account for biomass could be developed in different families. This may be partly attributed to the fact that most of the families are combinations of only some parental clones and thus are genetically related. Families sharing a common parent have a genetic relationship among them equivalent to that of halfsibs (covariance $\mathrm{COV}=1 / 4 \mathrm{~V}_{\mathrm{A}}$ ). Clones SAM259, SAM315, SAM44, and SAM282 of $S$. amygdaloides, and ERIO263 and ERIO292 of S. eriocephala, were used as parents twice in the full-sib families; clone ERIO16 served as a parent in five families. Full-sib families presented less variability than half-sibs and were characterized by simpler models.

Some models developed were linear and the rest, which included transformed covariables, were polynomials. Polynomial models have been used broadly in describing plant growth (Erickson 1976), height-diameter interactions (Ker and Smith 1955), and in many cases biomass produc- tion (Parde 1980 and references therein). Both types of models are provided in this study, nevertheless the non-linearity of growth (Promnitz 1974) indicates a reduced biological significance of the linear models. The models are complicated and difficult to interpret biologically. They deviate from the simpler approach of regarding growth and biomass production as a function of the height $\times$ diametersquare product. This function has found successful application in similar research in Scandinavia (Verwijst and Nordh 1992), where only one or two clones are present in large plantations, thus simplifying growth estimation approaches. The high numbers of species, families and clones present in the North American programs (mainly due to the early stage of these programs, but also due to genetic diversity considerations), warrant the development of estimation models at the family level, even though such models are usually statistically complicated. The bridge between statistics, morphometrics and applied biology is essential in the development of breeding and operational 
systems in plants, especially in the case of willows which are now becoming domesticated crop species. The advancement of growth models for biomass may also be useful to the debate on ideotype trees (Zsuffa and Aravanopoulos 1992) and their potential development. If industrial plantations consisting of a small number of clones are developed in North America, then a more sophisticated modelling approach will be required for accurate growth estimation.

\section{Acknowledgements}

The authors wish to acknowledge the input received by Dr. A. Mosseler, and the Laboratory of Forest Genetics personnel for their assistance. The Ontario Ministry of Natural Resources is acknowledged for the nursery facilities provided by the Ontario Tree Improvement and Forest Biomass Institute, Maple, Ontario. Financial assistance from the University of Toronto, the Faculty of Forestry and the International Energy Agency's Bioenergy Agreement Task VIII to FAA is thankfully acknowledged. Thanks are also due to Dr. D. Burgess for reviewing an earlier draft of this paper.

\section{References}

Argus, G.W. 1896. The genus Salix (Salicaceae) in the southeastern United States. Systematic Botany Monographs 9: 1-170.

Auclair, D. and A. Cabanettes. 1981. Method for estimation of above growth biomass and biomass production in classical coppice and first results. Pages 216-221 In: Palz, W., P. Chartier and D.O. Hall (Eds.). Energy from Biomass. First E.E.C. Conference. Baskerville, G.L. 1965. Dry matter production in immature fir stands. Forest Science No. 11 Monograph No. 9.

Berry, A.B. 1973. Production of dry matter from aspen stands harvested in short rotations. Pages 201-217 In: Young, H.E. (Ed.). I.U.F.R.O. Biomass studies.

Erickson, R.O. 1976. Modelling of plant growth. Annual Review of Plant Physiology 27: 407-434.

Ker, W.J. and J.H.G. Smith. 1955. Advantages of the parabolic expressions of height-diameter relationships. Forest Chronicle 31: $236-246$.

Kozak, A. 1973. Notes on the use of conditioned regressions in forestry. Pages 113-126 In: Warren W.G. (Ed.). Statistics in Forest Research

Ledig, T.F. 1974. Concepts of growth analysis. Pages 113-126 In: Reid, C.P.P. and G.H. Fechrer (Eds.). Proc. 3rd North American
Biology Workshop, 9-12 September 1974. College of Forestry and Natural Resources Colorado State University, Fort Collins.

McClave, J.T. and F.H. Dietrich. 1982. Statistics. 2nd ed. Dellen Publ. Comp. San Francisco, 766 p.

Mosseler, A.J. 1987. Interspecific hybridization and reproductive barriers between some North American willow species. Ph.D. Thesis Faculty of Forestry. University of Toronto. 286 p.

Mosseler, A., L. Zsuffa, M.U. Stoehr and W.A. Kenney. 1988. Variation in biomass production, moisture content and specific gravity in some North American willows. Can. J. For. Res. 18: 1535-1540.

Nemeth, G.C. 1973. Forest biomass estimation: permanent plots and regression techniques. Pages 173-175 In: Warren, W.G. (Ed.). Statistics in Forest Research.

Parde, J. 1980. Forest biomass. Forestry Abstracts 41: 343362.

Promnitz, L.C. 1974. Sampling and statistical problems in growth analysis. Pages 183-195 In: Reid, C.P.P. and C.H. Fechrer (Eds.). Proc. 3rd North American Forest Biology Workshop, 9-12 September 1974. College of Forestry and Natural Resources, Colorado State University, Fort Collins.

Ribe, J.H. 1973. A study of multistage and dimensional analysis sampling of puckerbrush stands. Pages 119-130 In: Young, H.E. (Ed.). I.U.F.R.O. Biomass studies.

Schaegel, B.E. 1975. Estimating aspen volume and weight for individual trees, diameter classes, or entire stands. U.S.D.A. Forestry Service, General Technical Report, NC-20. 16p.

Stott, K.G. 1984. Improving the biomass potential of willow by selection and breeding. Pages 233-260 In: Perttu, K. (Ed.). Ecology and Management of Forest Biomass Production Systems. Dept. Ecol. and Environ. Research Swedish Univ. Agric. Sci. Report 15.

Swank, W.T. and H.T. Shreuder. 1974. Comparison of three methods of estimating surface area and biomass for a forest of young Eastern White Pine. Forest Science 20: 91-100.

Verwijst, T. and N.-E. Nordh. 1992. Non-destructive estimation of biomass of Salix dasyclados. Bioresource Technology 41: 59-63.

Zsuffa, L. 1983. Aspects of short rotation forest farming in Canada. Pages 101-109 In: Proc. Workshop on development and utilization of Ligno-cellulosic raw materials, Nuclear Research Establishment, Julich, Germany, Nov. 20-22 1983.

Zsuffa, L. and F.A. Aravanopoulos. 1992. Genetic control of ideotype characters in Salicaceae. Silva Fennica (in print). 